\title{
RESEARCH SCHOOL FOR ANIMAL PRODUCTION AND HEALTH - A DESCRIPTION OF A DANISH INITIATIVE
}

\author{
Pia Haubro Andersen \\ Royal Veterinary and Agricultural University, Denmark
}

Research School for Animal Production and Health (RAPH) was founded in 1998, as a sibling to Research Centre for the Management of Animal Production and Health (CEPROS). Both institutions were founded mainly because Danish agriculture needed research and researchers who were capable of solving complex multidisciplinary problems associated with impaired animal health and welfare.

Formally, RAPH is part of the Graduate School for Veterinary and Agricultural Sciences in Denmark and is formed by The Royal Veterinary and Agricultural University in collaboration with a group of Danish research institutions. It has its own $\mathrm{PhD}$ programme which operates under the auspices of the general $\mathrm{PhD}$ programme. It has its own Head, a scientific board, and administrates its own funding. Currently $37 \mathrm{Ph} . \mathrm{D}$. students are enrolled in the programme, and 9 more will be enrolled during the remaining project period.

The principal objective of RAPH is to attract and train $\mathrm{PhD}$ students in multidisciplinary aspects of animal health and production. The School also aims to encourage and stimulate collaboration between university research centres in $\mathrm{PhD}$ training. In pursuing these aims, $\mathrm{RAPH}$ is committed to exploring new ways of organizing PhD studies.

The RAPH PhD students will gain competence in interdisciplinary aspects of production animal research, with a particular awareness of issues in animal health and welfare. The majority of their projects are planned at the borderline between two disciplines, for example Pathology and Clinical Science. RAPH PhD students will also achieve considerable insight into professional, ethical, legal and socio-cultural issues raised by the uses of production animals. Many researchers today have no or only little idea of the ethics involved in their decision as researchers. And many researchers tend to believe that ethics just is a matter of how well - or bad - you treat you experimental animals. "Ethics in Science" - is therefore a mandatory course (-or curse, as it is nicknamed by the students..) in RAPH. The course aims at enabling the student to analyse selected ethical and methodological problems which arise in research covering livestock production and health. The ethical problems include general animal ethics; ethics in connection with livestock production; ethics in connection with the interaction between research and livestock production and related ethical problems. Researchers ethics (publication ethics, norms for collaboration) is covered in detail. Finally, RAPH students are expected to become conversant with a wide range of research traditions, including qualitative research principles.

The Danish PhD curriculum is only 3 years. It is a very short time span, and besides the mandatory courses (Ethics in Science and Advanced Statistics) we encourage the students to go abroad, to engage themselves in the School and to follow our seminars and summer schools. The compression of the curriculum is - as we see it - one the major draw backs of the School today. 